\title{
Quantitative Variation in Calcium Carbonate Content in Shell of Different Chicken and Duck Varieties
}

\author{
Nimisha Ajayan, Shahanamol K. P, Arun A. U.", Shalu Soman \\ Department of Zoology, St. Peter's College, India
}

Received July 24, 2019; Revised December 23, 2019; Accepted December 25, 2019

\begin{abstract}
Copyright $\mathrm{C} 2020$ by authors, all rights reserved. Authors agree that this article remains permanently open access under the terms of the Creative Commons Attribution License 4.0 International License
\end{abstract}

\begin{abstract}
A comparative analysis of calcium carbonate content in the egg shells of eight selected chicken species (Naadankozhi ,Karinkozhi, Giriraja, White leghorn, Black silky, Porukozhi, Naked neck hen and White silkie) and six species of ducks (Vigova, Chara, Chembelli, Plain duck, Nadan Tharavu and Patha Tharavu) were conducted. It was noted that even though higher level of calcium was present in all variety of egg shells, in chicken variety the highest calcium carbonate was noticed in Aseel (Porukozhi) eggshell and it was $92.90 \%$ of $\mathrm{CaCO}_{3}$ and the lowest was in Silky's chicken egg shell and it was $86.75 \%$ of $\mathrm{CaCO}_{3}$. In duck the highest calcium carbonate was noticed in Plain duck and it was $91 \%$ whereas the minimum noted was in Patha Tharavu and its egg shell containing $75 \%$ of $\mathrm{CaCO}_{3}$. Amount of calcium carbonate always associated with the hardness and strength of the egg shell. Hence Porukozhi's egg shell has highest hardness and White silkie species has lowest. In ducks plain duck showed high hardness and patha tharavu with minimum.
\end{abstract}

Keywords Calcium Carbonate, Egg Shell, Chicken, Duck

\section{Introduction}

Birds are a group of endothermic vertebrates, characterised by feathers, toothless beaked jaws, the laying of hard shelled eggs, a high metabolic rate, a four chambered heart, and a strong yet light weight skeleton. The chicken (Gallus gallus domesticus) is a type of domesticated fowl, a sub species of the red jungle fowl. It is one of the most common and wide spread domestic animals, with a total population of more than 19 billion as of 2011 . There are more chickens than any other bird or domesticated fowl. Humans keep chickens primarily as a source of food and more rarely, as pets.

Poultry is one of the fastest growing segments of agricultural sector in India. Though the production of agricultural crops has been rising at a rate of 1.5 to $2 \%$ per annum, the production of eggs and broilers has been rising at a higher rate ( 8 to $10 \%$ per annum). Today India is world's fifth largest egg producer and the eighteenth largest broiler producer. As per livestock census 2007, the duck population of India is 27.43 million constituting 8.52 percent of the total poultry population. In normal cases, eggshell contain 95\% $\mathrm{CaCO}_{3}, \quad 3 \%$ Phosphorus, 3\% Magnesium and traces of $\mathrm{Na}, \mathrm{Zn}, \mathrm{Mn}, \mathrm{Fe}$ and $\mathrm{Cu}$. A good quality eggshell will contain, on average, 2.2 grams of calcium in the form of calcium carbonate. The distribution and demographic dynamics of duck population revealed that they are concentrated in Eastern, North eastern and southern states of the country. Duck farming in India is characterized by nomadic, extensive, seasonal and is still held in the hands of small and marginal farmers and nomadic tribes.

The eggshell of birds plays an important role in determining the physical and antimicrobial defense of the egg and regulates the exchange of metabolic gases and water (Hincke et al., 2012). Eggshells are waste materials from hatcheries, homes and fast food industries (Bain, 1997; Nys, et al., 2004,) and can be readily collected in plenty. Eggshell waste disposal contributes to environmental pollution. Challenges associated with disposal of eggshells include cost, availability of disposal sites, odour, flies and abrasiveness (Amu et al., 2005). Eggshell is non-edible by-product with little saleable value but they may contain biologically active compounds (Nakano et al., 2003). Calcium is the major component in an eggshell. There is also a small amount of magnesium in the eggshell and trace amounts of other micro elements (Swetha et. al., 2018). The composition of the egg shell is approximately 98.2, $0.9, \quad 0.9 \%$ Calcium carbonate, Magnesium and Phosphorous (phosphate) respectively. The outer egg shell is made almost entirely of calcium carbonate and is covered with as many as 17000 tiny pores. Many factors are known to be related to eggshell quality 
including: adequacy of nutrition, flock health problems, management practices, environmental conditions, and breeding. However, eggshell is a valuable source material or additive for numerous branches of the industry, such as, fodder and fertilizer producers, paper manufacturers. Numerous types of collagens, hyaluronic acid, or amino acids of interest may be extracted from the egg shell membrane and purified for numerous uses (e.g. dietary supplements, cosmetics), which makes the separated eggshell a highly valuable material (Gaonkar and Chakraborty, 2016). This way the egg producers could avoid the cost of waste disposal, moreover they can make extra profit by selling their side product (Gaonkar and Chakraborty, 2016). The eggshell is composed of calcite, which is one of the crystalline forms of calcium carbonate. An egg shell represents an approximate $10 \%$ of the total weight of the egg and its role is to protect its content, because of its hardness and thickness.

India's egg production will soon touch 100 billion annually from 90 billion per year as the poultry sector is growing rapidly and becoming an organized small scale sector (Shwetha et al., 2018). Estimated egg production from Kerala was about 2.44 billion eggs during 2015-2016, which accounted $2.95 \%$ of the total eggs produced in India. Eggshells take a long time to compost as compared to other types of wet waste like peels, seeds etc. Hence accumulation of egg shell is a reality and need some special provision to make use this waste. To initiate a move in this direction it is necessary to find the $\mathrm{CaCO}_{3}$ percentage of egg shells of hen and ducks. Hence this study is aimed to find the amount of $\mathrm{CaCO}_{3}$ in shells of birds especially hen and ducks.

\section{Methodology and Materials}

\subsection{Eggshell Sample}

A basic field study was conducted to detect different varieties of chicken and ducks available in the locality. As the number of different varieties of chickens and ducks were less in the local area, poultry farms were selected for egg collection. The chicken varieties include Nadankozhi, Giriraja, Black silkie, White silkie , Karinkozhi, Porukozhi and Naked neck hen, whereas the duck includes Vigova, Chara, Chemballi, Plain duck, Nadan tharavu and Patha duck. Standard procedures were used in this study. The methodology adopted in this study was "Acid base titration" (Shwetha et al., 2018).

\subsection{Determination of $\mathrm{CaCO}_{3}$ in an Egg Shell}

The Major component of eggshell is Calcium Carbonate
$\left(\mathrm{CaCO}_{3}\right)$. This analysis will be done volumetrically by using a characteristic reaction of carbonate compounds, namely their reaction with acids. Calcium Carbonate (limestone) is very insoluble in pure water but will readily dissolve in acid according to the reaction.

$$
\begin{aligned}
& 2 \mathrm{HCl}(\mathrm{aq})+\mathrm{CaCO}_{3}(\mathrm{~s}) \rightarrow \mathrm{Ca}_{2}+(\mathrm{aq})+\mathrm{CO}_{2}(\mathrm{~g})+\mathrm{H}_{2} \mathrm{O} \\
& +2 \mathrm{Cl}-(\mathrm{aq})
\end{aligned}
$$

This reaction cannot be used directly to titrate the $\mathrm{CaCO}_{3}$ because it is very slow when the reaction is close to the endpoint. Instead the determination was achieved by adding on excess of acid to dissolve all of the $\mathrm{CaCO}_{3}$ and then titrating the remaining $\mathrm{H}_{3} \mathrm{O}+$ with $\mathrm{NaOH}$ solution to determine the amount of acid which has not reacted with the calcium carbonate. The difference between the amount of the acid $(\mathrm{HCl})$ initially added and the amount left over after the reaction was equal to the amount used by the $\mathrm{CaCO}_{3}$. The reaction used to determine the leftover acid is

$$
\mathrm{HCl}(\mathrm{aq})+\mathrm{NaOH}(\mathrm{aq}) \rightarrow \mathrm{H} 2 \mathrm{O}+\mathrm{Na}+(\mathrm{aq})+\mathrm{Cl}-(\mathrm{aq})
$$

In each category six samples were taken for analysis and standard error was calculated using SPSS and standard graph were plotted using MS Excel.

\section{Observation and Result}

The amount of $\mathrm{CaCO}_{3}$ determined the strength of the egg shell. It was not that each variety of chicken and duck has its own specific percentage of calcium carbonate in their egg shell but the average value of calcium in all the selected eggs were $89.40 \%$. The result showed that the percentage of calcium Carbonate varying from $92.90 \%$ (Azeel) to $86.65 \%$ (Silky) (graph 1). The common breed Giriraja showed a comparative good calcium content in their egg shell $(92.90 \%)$. Other chicken varieties showed marked variations in their calcium carbonate content, the calcium content was, Karinkozhi (90.15\%), White Leghorn (87.45\%), Naadankozhi (90.22\%), White silkie (86.75\%), and Black silkie (89.06\%).

Besides this the mount of calcium carbonate was determined in six varieties of duck egg shell. Varieties include Vigova, Chara, Chembelli, Plain duck, Nadantharavu and Patha tharavu. The result obtained showed that egg shell of the plain duck has high $\mathrm{CaCO}_{3}$ content $(91 \%)$. Least amount of calcium carbonate noticed in Patha Tharavu (75\%) (Graph2). Other duck varieties showed marked variations in their calcium carbonate content, Nadan Tharavu (86\%), Chara (84\%), Chembaly (90\%) and Vigova (80\%).

It was noted that the average percentage of Calciums Carbonate is higher in chicken verities $(89.05 \%)$ when compare with ducks (84.63) (Graph. 3). 


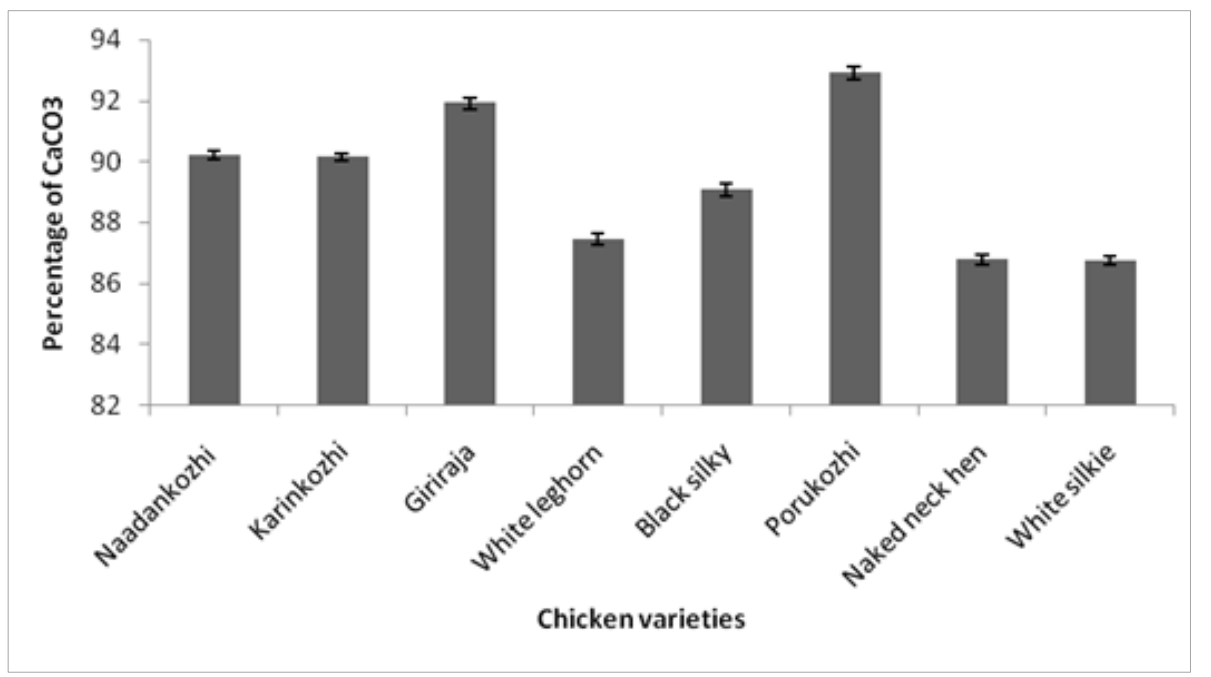

Graph 1. Showing the mass percentage of calcium carbonate present in different varieties of chicken eggshells

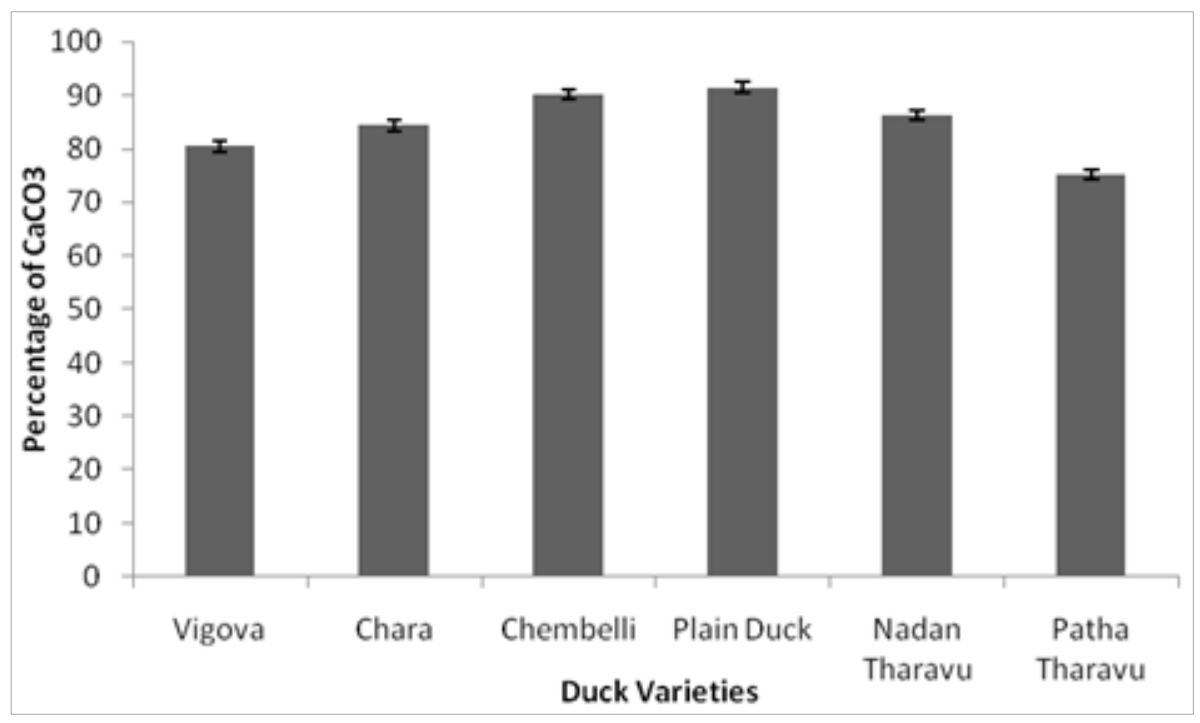

Graph 2. Showing the mass percentage of calcium carbonate present in different varieties of duck eggshells

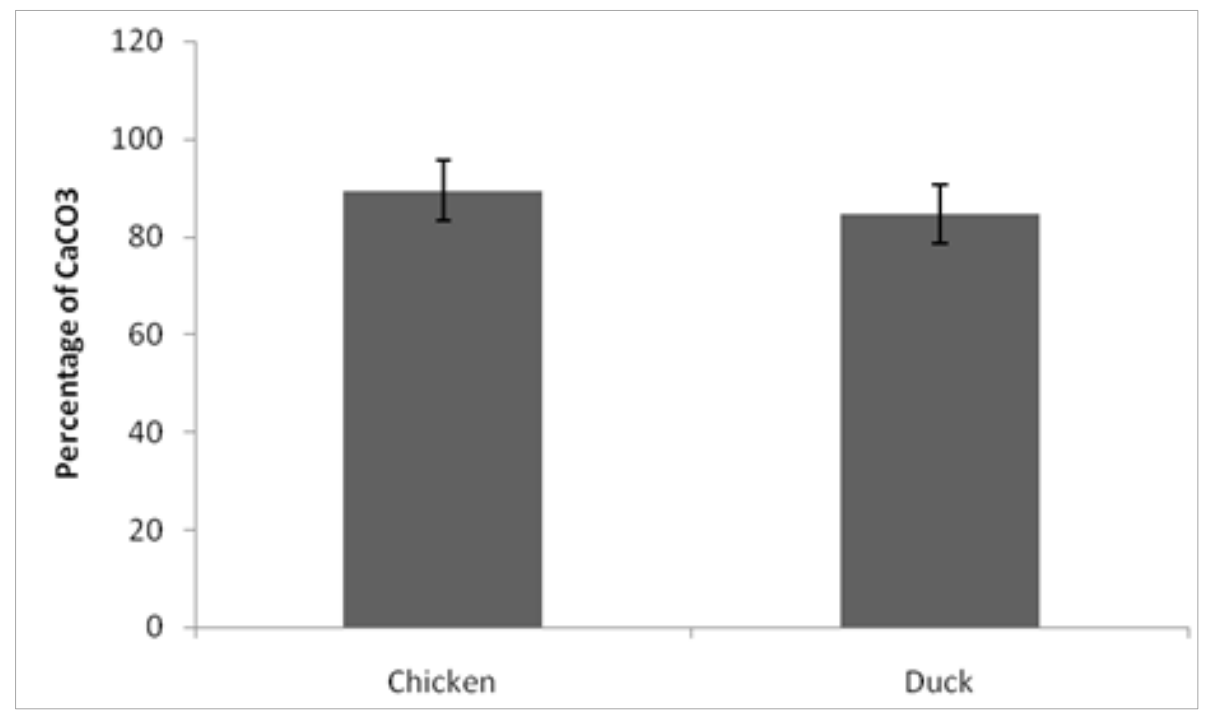

Graph 3. Average Percentage of $\mathrm{CaCO} 3$ in chicken egg shell and Duck egg shell 


\section{Discussion}

The amount of calcium carbonate is different in different varieties of chicken eggshells. Among the eight varieties of chicken, it was noted that Aseel (92.90\%) chickens eggshell have the highest amount of $\mathrm{CaCO}_{3}$ and White silkie $(86.75 \%)$ chickens eggshell have the minimum amount of calcium carbonate. It can be concluded that dark coloured egg shell have more calcium carbonate when compared to the white coloured egg shell. Similar results have been noticed by many workers (Hincke, et al., 2008, Gautron et al., 1996). The comparative analysis of calcium carbonate content was carried out for selected eggshell of hen ,duck and guinea fowl by using back titration method, it was noted that Guinea fowl eggshell with brown colour egg is the best sources of calcium when compare to others. (Gautron et al., 2011). It is proved that brown eggshells contain more calcium carbonate than white eggshells have and this may due to the difference in hens diet (Hunton 2005). Brown egg has a higher percentage of calcium $(82.25 \%)$ than the white egg $(75.82 \%)$, it indicate brown egg has a higher strength than white egg (Hincke, et al., 2012).

According to Shen and Chen (2003) the duck eggshells contained higher calcium and lower magnesium. In ducks, the magnesium content in the eggshell was not affected by dietary magnesium levels (Shen and Chen, 2003). Eggshells can be utilized for various purposes that minimize their effect on environmental pollution (King'ori, 2011). Eggshells present healthy, balanced calcium is due to its trace amounts of other minerals and is probably the best natural source of calcium (Adeyeye, 2009). The palisade layer $(5000 \times)$ of the eggshell was compact for ducks, but had many hollow vesicles in the chicken eggshell. In a comparative study it is noted that hen egg shell contains more calcium than that of Duck egg shell. According to Wei Chen et al. (2015) dietary calcium deficiency negatively affects eggshell quality and microarchitecture, probably by suppressing shell biomineralization.

\section{Conclusions}

Though nitrogen, phosphorus, and potassium are most vital for healthy growth, calcium is also essential for building healthy "bones". Eggshells are naturally abrasive but don't contain the toxic chemicals that find in store-bought cleaners. Hence this study enable to find the total carbonate content in the egg shell of chickena and duck, and enlighten the common men for the utilization of egg shell as a calcium and magnecium supplement for the growth and development of animals and plants.

\section{Acknowledgements}

The authors thank the Principal, St.Peter's College, Kolenchery for the permission and help rendered during the study.

\section{REFERENCES}

[1] Adeyeye EI. 2009.Comparative study on the characteristics of Egg Shells of some bird species. Bull. Chem. Soc. Ethiop. 23(2): 159-166

[2] Amu OO, Fajobi AB, Oke BO. 2005.Effect of eggshell powder on the stabilizing potential of lime on an expansive clay soil. Res. J Agric. \& Biol. Sci.. 1: 80-84.

[3] Bain M. A 1997.Reinterpretation of eggshell strength. In: Solomon S.E. (ed.): Egg and Eggshell Quality. Manson Publishing Ltd., London, UK, 131-141.

[4] Gaonkar Madhavi and, Chakraborty A.P.2016. Application of Eggshell as fertilizer and Calcium Supplement Tablet. International Journal of Innovative Research in Science, Engineering and Technology.5(3): 3520-3525.

[5] Gautron,J, MT Hincke, M Panheleux, M Bain, MD McKee, SE Solomon, Y Nys.2011: Ovocalyxin-32, a novel chicken eggshell matrix protein. Isolation, amino acid sequencing, cloning, and immunocytochemical localization. J Biol Chem 276: 39243-39252.

[6] Gautron J, M Bain, S Solomon, Y Nys: 1996.Soluble matrix of hen's eggshell extracts changes in vitro the rate of calcium carbonate precipitation and crystal morphology. $\mathrm{Br}$ Poult Sci 37, 853-866

[7] Hincke M.T. O Wellman-Labadie, MD McKee, J Gautron, Y Nys, K Mann: 2008.Biosynthesis and structural assembly of eggshell components. In: Egg Bioscience and Biotechnology, Chapter 2. Ed: Mine Y. John Wiley and Sons, Hoboken, USA.

[8] Hincke T. Maxwell, Yves Nys, Joel Gautron, Karlheinz Mann, Alejandro B. Rodriguez-Navarro and Marc D. McKee. 2012. The eggshell: structure, composition and mineralization. Frontiers in Bioscience 17: 1266-1280.

[9] Hunton P.2005.Research on eggshell structure and quality: an historical overview. Brazilian Journal of Poultry Science. 7: $67-71$.

[10] Nakano T, Ikawa NI, Ozimek L. 2003.Chemical Composition of Chicken Eggshell and Shell Membranes. Journal of Poultry Science. 3:510-514.

[11] Nys Y, J Gautron, JM Garcia-Ruiz, MT Hincke.2004. Avian eggshell mineralization: biochemical and functional characterization of matrix proteins. Comptes Rendus Paleovol 3: 549-562.

[12] Shen T F,and Chen W.L.2003. The Role of Magnesium and Calcium in Eggshell Formation in Tsaiya Ducks and Leghorn Hens. 16(2): 290-296. 
[13] Shwetha A, Dhananjaya, Shravana Kumara SM, Ananda.2018. Comparative study on calcium content in egg shells of different birds. International Journal of Zoology Studies. 3(4): 31-33.

[14] Wei Chen, Fei Zhao, Zhi Mei Tian, Han Xing Zhang, Dong Ruan, Yan Li, Shuang Wang, Chun Tian Zheng, Ying Cai Lin. 2015. Dietary calcium deficiency in laying ducks impairs eggshell quality by suppressing shell biomineralization. Journal of Experimental Biology. 218: 3336-3343.

[15] 15. King'ori A M.2011 Review of the Uses of Poultry Eggshells and Shell Membranes. International Journal of Poultry Science 10 (11): 908-912. 